We try to publish authors' responses in the same edition with readers' comments. Time constraints might prevent this in some cases. The problem is compounded in a bimonthly journal where continuity of comment and redress are difficult to achieve. When the redress appears 2 months after the comment, 4 months will have passed since the article was published. Therefore, we would suggest to our readers that their correspondence about published papers be submitted as soon as possible after the article appears.

\section{Diagnosis of Bacterial Sinusitis}

To the Editor: I would like to comment on the article written by Drs. Little, Mann, and Godbout regarding acute sinusitis (Little DR, Mann BL, Godbout CJ. How family physicians distinguish acute sinusitis from upper respiratory tract infection: a retrospective analysis. J Am Board Fam Pract 2000;13:101-6). This article is well written, but I believe it is typical of the bias that is now present in our literature and unfortunately does not help clarify a difficult antibiotic-prescribing problem.

First, sinusitis is a location diagnosis, not an etiologic diagnosis, and therefore must be clearly differentiated from acute viral sinusitis, acute bacterial sinusitis, and acute allergic sinusitis. Many of today's articles and certainly the public seem to equate the terms sinusitis, bronchitis, pneumonia, and several other location descriptions with the assumption of bacterial illness, which is certainly not the case.

Second, there is unavoidable bias in retrospective analysis. The pressures of reimbursement coding and the scrutiny of peer review encourage physicians to label and document to justify treatment decisions. Thus, if I am going to diagnose a bacterial infection, I will dictate the salient features that will support my diagnosis. I also have a strong tendency to code the "-itis" diagnosis when the infection is bacterial and the upper respiratory tract diagnosis when the illness is viral. As a case in point, I was recently audited by my local health maintenance organization on antibiotic use in bronchitis and was found to be too high in my prescribing. For many years $I$ have been extremely conservative with antibiotics, and as a result, I have had to deal with several unhappy patients. The problem was that I coded bronchitis when a patient was sick more than 10 days and coughing, whereas I coded upper respiratory infection for a patient who was sick only a few days and coughing.

I do not know how to get a uniform description of what constitutes viral vs bacteria symptoms and signs, but I do believe our literature must not only be very clear in the usage of terminology but must also concentrate on well-controlled prospective evaluations and forget retrospective reviews.

Howard Weinberg, MD

Virginia Beach, $\mathrm{Va}$
The above letter was referred to the corresponding author of the article in question, who offers the following reply.

To the Editor: Thank you for the opportunity to respond to Dr. Weinberg's comments concerning our article on the diagnosis of acute bacterial sinusitis. 'I appreciate his interest in the article, his perspectives on the challenge of diagnosing this condition, and his recognition of the difficulties inherent in studying physician practice patterns in this area.

Dr. Weinberg points out the possibility of sinusitis representing imprecise language being used to imply an acute bacterial infection when there might be other causative factors. This assertion is consistent with the recent Evidence Report issued by the Agency for Health Care Research and Quality (AHRQ). ${ }^{2}$ The AHRQ report uses the more precise term "acute bacterial rhinosinusitis." One of the objectives of our study, however, was to examine physicians' use of the diagnostic terminology in this context. Our finding that $98.4 \%$ of patients with a diagnosis of sinusitis received antibiotic therapy indicates that the physicians studied do indeed apply this term to cases of suspected bacterial infection.

Dr. Weinberg also raises the issue of the limitations of retrospective analysis in studying clinical issues. Our article acknowledged these limitations as well. The purpose of this study, however, was to examine physician practice patterns. Any other methodology would introduce an obvious observation bias, as physicians can behave differently in situations where they are being observed. This limitation is far greater to understanding clinical decision making. Dr. Weinberg's experience with the diagnosis of bronchitis illustrates that point very clearly. This anecdote is only partially relevant to our study, because the benefits of antibiotic therapy for bronchitis are much less convincing than for sinusitis. ${ }^{3}$ But as Dr. Weinberg describes, his practice is to establish a clinical diagnosis, then record the observations that he considers most pertinent to justify the diagnosis and management plans. This is precisely the rationale we used in designing our methodology-that physicians record the details of the illness they consider most pertinent in determining the diagnosis. This illustration confirms our methodology and reinforces the validity of our findings about physician practice patterns.

In summary, both our data and the anecdote provided by $\mathrm{Dr}$. Weinberg reinforce the idea that the clinical diagnosis of respiratory infections is influenced by physician practice patterns. As a result, these patterns need to be examined. We share Dr. Weinberg's concern about the limitations of the retrospective methodology, and we have also approached this question using a simulated case history. ${ }^{4}$ Prospective evaluations of physician practices 
are equally fraught with methodologic challenges, especially observation bias.

David R. Little, MD, MS

Wright State University

Dayton, Ohio

\section{References}

1. Little DR, Mann BL, Godbout DF. How family physicians distinguish acute sinusitis from upper respiratory tract infection: a retrospective analysis. J Am Board Fam Pract 2000;13:101-6.

2. Diagnosis and treatment of acute bacterial rhinosinusitis. Summary evidence report/technology assessment: no. 9. Rockville, Md: Agency for Health Care Policy and Research, 1999.

3. Smuchy JJ, Becker LA, Glazier RH, McIssac W. Are antibiotics effective treatment of acute bronchitis? A metaanalysis. J Fam Pract 1998;47:453-60.

4. Little DR, Mann BL, Sherk KW. Factors influencing the clinical diagnosis of sinusitis. J Fam Pract 1998;46:147-52.

\section{Uterine Inversion}

To the Editor: I am writing regarding your recently published article "Uterine Inversion: a Life-Threatening Obstetric Emergency." Drs. Hostetler and Bosworth state that "the most likely cause [of uterine inversion] is strong traction on the umbilical cord ... during the third stage of labor." This statement is referenced to information from the 20th edition of Williams Obstetrics. The authors of this text do not reference where this opinion came from. In June 1995 Obstetrics and Gynecology Clinics of Nortb America published an article by Wendel and $\mathrm{Cox}^{2}$ on the management of uterine inversions. In their article they reference work by Schaefer and Veprosvsky from 1949 that included mismanagement of the third stage of labor as the cause of uterine inversion; then they go on to reference multiple studies that have disproved this theory. They state:

Modern reports, however, fail to show a direct association of inversion with mismanagement of the third stage of labor. In fact, $15 \%$ to $50 \%$ of inversions occur "spontaneously" after the third stage of labor. These recent findings suggest a congenital predisposition to inversion as a consequence of abnormalities of uterine musculature or innervation. Further supporting evidence for this theory is that the condition occasionally recurs in subsequent labors.

As textbooks often lag behind other bodies of knowledge, I think this might help clarify the medical myth that cord traction is the usual cause of uterine inversion.

Miles Rudd, Md

Warm Springs, Ore

\section{References}

1. Hostetler DR, Bosworth MF. Uterine inversion: a lifethreatening obstetric emergency. J Am Board Fam Pract 2000;13:120-3.
2. Wendel PJ, Cox SM. Emergent obstetric management of uterine inversion. Obstet Gynecol Clin North Am 1995; 22;261-73.

\section{Birth and Death: Through a Child's Eyes}

To the Editor: Dr. Feldman's response ${ }^{1}$ to my concerns about her advocating sibling presence at childbirth is even more worrying than her original article. ${ }^{2}$ Several of the studies she cites in support of her position do not in fact do so: one study ${ }^{3}$ does not deal with this subject at all. At least one other ${ }^{4}$ is not a scientific study but is the memoir of a sibling birth attendance written by members of a family in a rather self-justifying manner. Furthermore, several of the studies have serious methodological problems in that they use psychological instruments that were created ad hoc and not subjected to reliability and validity analyses, so that their usefulness in assessing the psychological impact of birth attendance on children remains to be shown. ${ }^{5}$ On the other hand, some of the articles Dr. Feldman cites illustrate very clearly the concerns expressed in my letter. A vivid description of the impact on children viewing the birth of a sibling is provided by Daniels ${ }^{6\left(\mathrm{p}^{20)} \text { : }\right.}$

There were very few cases without some expression of negative feelings ( 5 of 30 ); fear was the predominant negative emotion. The children who had the hardest times were probably those who perceived their mothers as helpless, in pain or out of control. One child thought her mother might die if the placenta did not come out. In one case, there was a hemorrhage that quickly responded to bimanual compression. The child was so nauseated that he had to leave.... In several cases, the mother's crying out persisted as a troublesome memory. A 5-yearold said to me, "Well, you see, there's crying. I am used to crying ... but screaming ...." During delivery she had buried her face in the support person's shoulder.

Another author ${ }^{7(\mathrm{p} 16)}$ cited by Dr. Feldman cautions: "there are several reasons to be cautious about extrapolating from (her own) findings:

3. The negative observations bade of some children by the midwives suggest the need for an independent observational study of child behaviors at birth.

4. The follow-up was short-term only" (emphasis in original)

Short-term, methodologically flawed studies should not decide this issue. Furthermore, the responses quoted from the children themselves graphically show the traumatic potential of attendance at sibling birth. It should be noted that these reactions occurred even though these children were prepared by a special program for children scheduled to witness sibling birth. Dr. Feldman claims that with preparation there is no danger to children in observing sibling birth.

Daniels $^{6\left(p^{21)}\right.}$ comments further: 